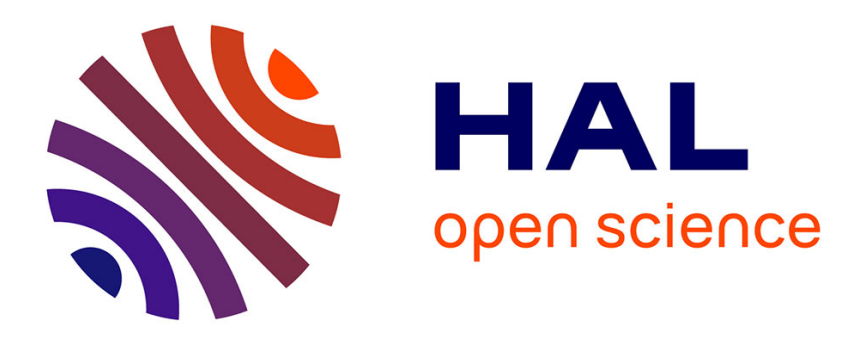

\title{
X-ray imaging with off-axis Bragg Fresnel multilayer lenses
}

\author{
A. Mirone, M. Idir, G. Soullie, P. Dhez
}

\section{To cite this version:}

A. Mirone, M. Idir, G. Soullie, P. Dhez. X-ray imaging with off-axis Bragg Fresnel multilayer lenses. Journal de Physique IV Proceedings, 1994, 04 (C9), pp.C9-273-C9-276. 10.1051/jp4:1994948 jpa00253509

\section{HAL Id: jpa-00253509 https://hal.science/jpa-00253509}

Submitted on 1 Jan 1994

HAL is a multi-disciplinary open access archive for the deposit and dissemination of scientific research documents, whether they are published or not. The documents may come from teaching and research institutions in France or abroad, or from public or private research centers.
L'archive ouverte pluridisciplinaire HAL, est destinée au dépôt et à la diffusion de documents scientifiques de niveau recherche, publiés ou non, émanant des établissements d'enseignement et de recherche français ou étrangers, des laboratoires publics ou privés. 


\title{
X-ray imaging with off-axis Bragg Fresnel multilayer lenses
}

\author{
A. Mirone $e^{*, * * *}$, M. Idir**,***, G. Soullie ${ }^{* *, * * *}$ and P. Dhez $*, * *$ \\ * Laboratoire de Spectroscopie Atomique et Ionique (LSAI), Université Paris Sud, 91405 Orsay cedex, \\ France \\ ** Laboratoire pour l'Utilisation du Rayonnement Electromagnétique (LURE), Université Paris Sud, \\ 91405 Orsay cedex, France \\ *** CEA, Service CEM/MR, BP. 12, 91680 Bruyères-le-Châtel, France \\ **** CARSO, Centre for Advanced Research in Space Optics, Dipartimento di Astronomia, Universita di \\ Trieste, Padriciano 99, Trieste, Italy
}

\begin{abstract}
We analyse the possibilities of using a new kind of Bragg Fresnel Multilayer Lens that we have designed in order to improve image contrast[1]. We discuss the aberrations and the dynamical properties of this lens on the base of a recently developed dynamical theory[2] and of the data from the first imaging tests that we have performed. The principle of the optimal configuration for utilisation of these lenses is given.
\end{abstract}

\section{INTRODUCTION}

Bragg-Fresnel Multilayer Lenses (BFML) are a recent optical element that casts together the reflectivity properties of multilayer mirrors and the focusing ones of Fresnel Zone Plates[3]. These devices are particularly suited to high fluxes applications.

We present a study of a new BFML design that has been recently proposed to overcome the loss of image contrast which is linked to the presence of several diffraction orders[2].

The off-axis principle, that we recall in figure 1, is based on order separation and allows the reduction of the background around the focused spot.

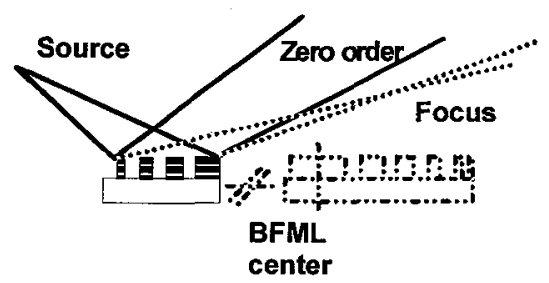

Figure 1: Geometrical view of the off-axis BFML
principle. Orders separation is achieved by a shift to
off-axis in classical diffraction (beam perpendicular
to grooves).

In the energy range where BFMLs have been used so far $(E>1 \mathrm{Kev})$, the glancing angle is small $(\theta<10$ $\mathrm{deg}$ ). Highly off-axis designs can be achieved without exceeding the writing apparatus limitations because the zone size in the direction of classical diffraction (beam perpendicular to the grooves) is greater by a factor $1 / \sin (\theta)$ than in the case of an equivalent transmission Fresnel Zones Plate.

Figure 2 shows the images of a $1750 \mathrm{eV}$ collimated beam produced by a linear off-axis BFML, whose parameters are reported in caption. The signal has been recorded by a proportional counter scan for different glancing angles of the incident beam.

Each diffraction order peak in figure 2 is optimised at a different glancing angle. This behaviour is similar to the one of multilayer gratings in which the Bragg law links energy, grating diffraction order and glancing angle at the Bragg peaks. 
For highly off-axis design, if the angular separation of diffracted orders is larger than the angular width of the Bragg peak, only one reflected order at time can be observed with monochromatic beam.

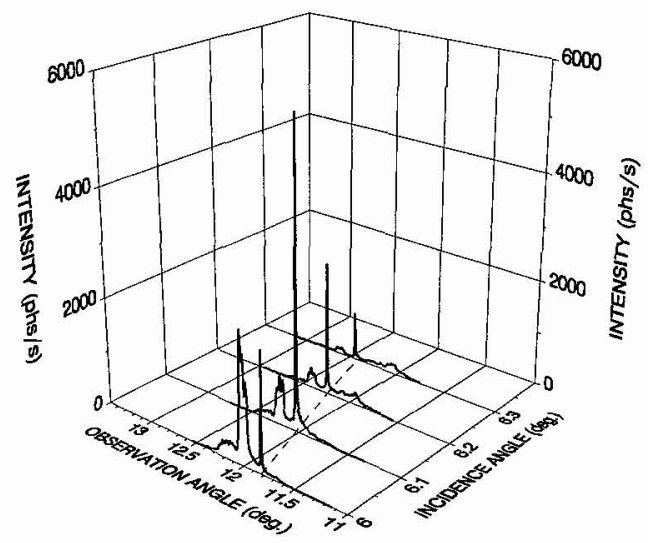

\begin{abstract}
Figure 2 : Proportional detector intensity versus detector angle for the off-axis BFML at four different incidence angles. The $B F M L$ is made on a multilayer coating composed of $65 \mathrm{~W} / \mathrm{Si}$ bilayers 34 Angstrom thick. The lens is located between the 1000th and 1500th grooves of a centred $B F M L$ having $15 \mathrm{~cm}$ focal length at $6.1 \mathrm{deg}$. glancing angle at $1750 \mathrm{eV}$.

The different orders can be selectively exited by tuning the incidence angle.
\end{abstract}

If such a highly off-axis BFML is used in white beam at a fixed incident glancing angle, all the reflected orders can be observed simultaneously, each order having its own Bragg energy.

Another remarkable property of off-axis design is the higher efficiency due to short local periods of the BFML. This property, already demonstrated for multilayer grating [4], is encountered in BFMLs when the extinction length of the beam is greater than the local BFML period.

Elliptical off-axis BFMLs have also recently been tested for $2 \mathrm{D}$ imaging. One result from these tests is reported in figure 3 . The tested elliptical lenses have the same parameters of the linear BFML of figure 2.

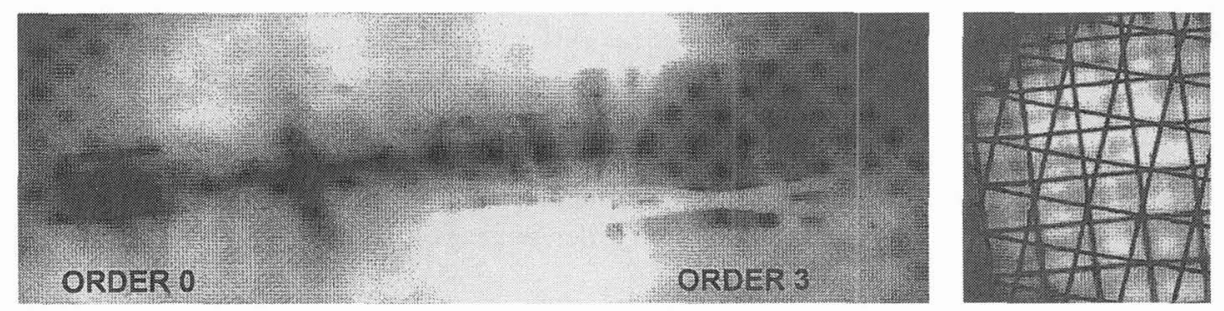

Figure 3: image of a test object at 1750eV using an off-axis elliptical BFML

On the right, one can see the optical microscope photography of the nickel grid (bar width $18 \mu \mathrm{m}$ ) which we used as a test object. On the left we report the grid image obtained at $1750 \mathrm{eV}$ (using InSb crystals) by placing the object at $7 \mathrm{~cm}$ and the emulsion at $22 \mathrm{~cm}$ from our off-axis BFML.

\title{
ABERRATIONS IN OFF-AXIS BFMLS AND THEIR REDUCTION
}

Chromatic aberrations are present in a lens if $1 / n$, where $n$ is the number of grooves, is smaller than the lens bandpass resolution $\triangle \mathrm{E} / \mathrm{E}$. In our off-axis BFMLs the above condition is broken and chromatic aberrations are needed to be taken seriously into account when a white beam is used.

In order to reduce chromatic aberration, we study the scheme of figure 4 where a linear BFML, located on the first element from the left, between $\mathrm{x}=-\mathrm{a}$ and $\mathrm{x}=\mathrm{a}$, focuses monochromatic radiation of wavelength $\lambda_{0}$ from point $\mathrm{S}$ to point $\mathrm{I}$.

The grating function $G(x)$ for this lens is defined by $\mathbf{G}(\mathbf{x})=\mathbf{s}\left(\mathbf{p}, \mathbf{x}, \theta_{0}\right)+\mathbf{s}\left(\mathbf{q},-\mathbf{x}, \theta_{1}\right)$ where $s(a, b, c)=\sqrt{a^{2}+b^{2}+2 a b \cos (c)}$, and where $p$ and $q$ are the distance of point $S$ and $I$ from the centre of the first lens. In the general case of off-axis BFMLs, $\theta_{0}$ is different from $\theta_{1}$. We recall that the profile 
of a BFML is chosen by placing the zone borders at positions $r_{n}$ such that $G\left(r_{n}\right)-G\left(r_{n-1}\right)=\frac{\lambda_{0}}{2}$. A lens designed in this way realises an aberration-free focusing from $S$ to $I$ for the wavelength $\lambda_{0}$.

Aberration occurs when we change the source parameters $\theta_{0}$ and $\lambda$. Let us consider the effect of a shift $\Delta$ $\lambda$ in the wavelength, leaving $\theta_{0}$ unchanged.

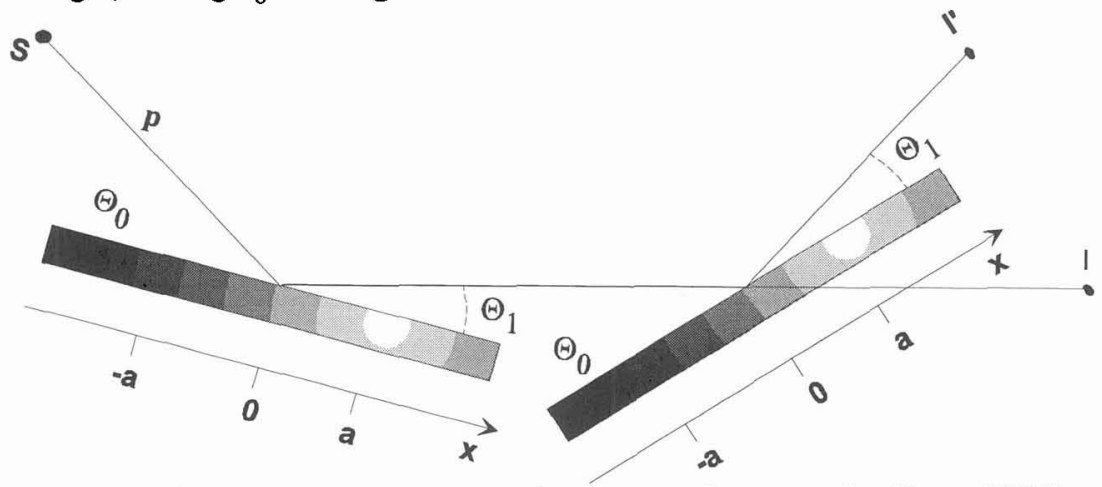

Figure 4: the principle of chromatic aberration reduction with off-axis BFMLs

The optical path function from the point source $S$ to the point $I$, is, for the new wavelength $\lambda=\Delta \lambda+\lambda_{0}$,

$$
P(x)=s\left(p, x, \theta_{0}\right)+s\left(q,-x, \theta_{1}\right)-\frac{\lambda_{0}+\Delta \lambda}{\lambda_{0}} G(x)=-\frac{\Delta \lambda}{\lambda_{0}} G(x)
$$

We can use for $\mathrm{s}$ the Taylor expansion up to second order in $\mathrm{x}$ and get

$P(x)=\frac{\Delta \lambda}{\lambda_{0}}\left(q+p+x\left(\cos \left(\theta_{1}\right)-\cos \left(\theta_{0}\right)\right)+\frac{x^{2}}{2}\left(\frac{\sin ^{2}\left(\theta_{0}\right)}{p}+\frac{\sin ^{2}\left(\theta_{1}\right)}{q}\right)\right)$

We can see from this equation that for off-axis BFML ( $\theta_{0}$ different from $\left.\theta_{1}\right)$, there is a new term linear in $\mathrm{x}$.

In our off-axis BFMLs, we are confronted with two opposite needs : on the one hand we want the greatest difference between $\theta_{0}$ and $\theta_{1}$, while, on the other hand, we want to limit the chromatic aberrations occurring with a white beam.

In the scheme of figure 4, the first order from the first BFML is diffracted once again as first order from the second lens. From a geometrical optics point of view, if the distance between lenses is small compared to $q$, a ray hitting at $x$ on the first lens, hits at $-\mathrm{x}$ on the second lens. This way the dangerous linear term of equation (3) is eliminated.

We have done a numerical simulation of a double reflection system. We considered two linear off-axis BFML working in classical diffraction, based on the same multilayer coating of the previously considered BFMLs

The focal distance of both lenses is $15 \mathrm{~cm}$ at $1750 \mathrm{eV}$ and the lenses are built between the 3400 th and 5400 th groove of a corresponding centred lens or, equivalently, between 8 and $10 \mathrm{~mm}$ from its center. The Bragg angle is about 6 degree, the lens projection in the direction of incident beam is $200 \mu \mathrm{m}$ wide and is $800 \mu \mathrm{m}$ far from the centre projection.

Figure 5 shows the numerical simulation for a double reflection system where the distance between lenses is $2 \mathrm{~mm}$. The calculation, based on a recently developed dynamical theory[2], is reported for two different wavelengths and shows, beside the reflectivity dependence on wavelength, a reduced chromatic aberration. A single off-axis lens would give a stronger chromatic aberration because the peaks would be 
shifted through a longer distance as the wavelength changes. This distance can be estimated as the product of the distance from the centre $(800 \mu \mathrm{m})$ and the percentual wavelength shift.

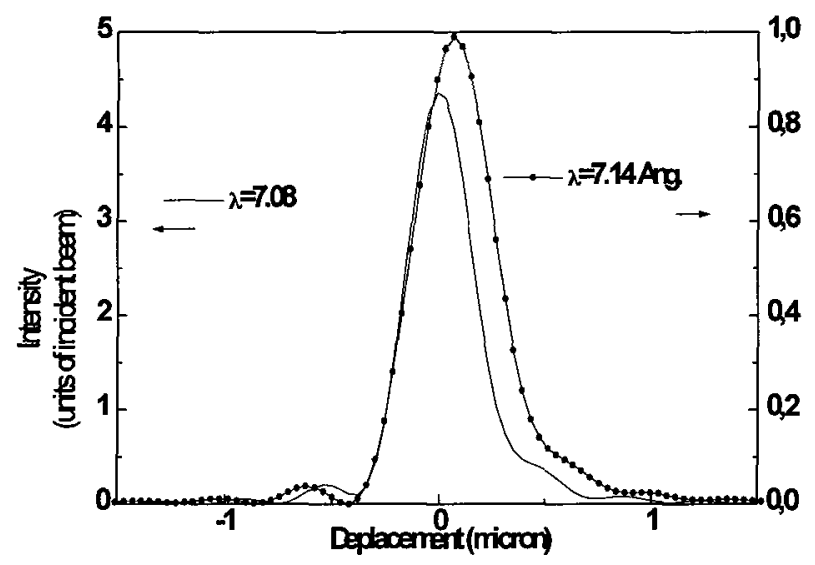

Figure 5 : Intensity at the focal plane of system composed by two off-axis BFMLs for two different wavelengths

\section{CONCLUSION}

We have reported recent results on x-rays imaging by off-axis BFMLs. The tests were performed with monochromatic radiation. To use these lenses with white beam we have proposed, on a theoretical basis, a double reflection scheme which reduces chromatic aberrations to the ones occurring in centred lenses.

This scheme has the advantage of decreasing considerably the noise around the focused spot, which could be due to the other diffraction orders. In a highly off-axis BFML, the different diffracted orders have considerably different Bragg energies from one another. The second BFML, in our scheme, diffracts selectively the first diffracted order from the first lens, which has the right angle and energy

\section{REFERENCES}

[1] A. MIRONE, M. IDIR, G. SOULLIE, Ph. GUERIN, FR. LADAN, H. LAUNOIS

P. DHEZ, "New design for Bragg-Fresnel Multilayer lenses", X-Ray Microscopy IV, Septembre 93 MOSCOU

[2] A. MIRONE, M. IDIR, P. DHEZ, G. SOULLIE, A. ERKO, "Dynamical theory for Bragg-Fresnel multilayer lenses for $X-U V$ and $X$-ray range", submitted to Optics Communications

[3] V.V. ARISTOV, A.ERKO, V.V. MARTYNOV "Principles of Bragg-Fresnel Multilayer Optics", Revue Phys. Appl. 23, (1988), 1623-1630

[4] A.I.ERKO, B.VIDAL, P.VINCENT, Yu.A.AGAFONOV, V.V.MARTYNOV, D.V.ROSCHUPKIN, M..BRUNEL, "Nuclear Instruments and Methods in Physics Research 1993 